\title{
DA HONRA AO MÉRITO: \\ UMA NARRATIVA RETROSPECTIVA SOBRE A ORIGEM DE UM CONCEITO MODERNO
}

\section{EDUARDO DE BORBA ${ }^{1}$}

\begin{abstract}
RESUMO: Neste artigo apresento uma narrativa que traça o surgimento da ideia de mérito de forma retrospectiva, isto é, buscando na passagem para a Modernidade seu espaço de gênese e ascensão. Para isso, início apresentando a emergência do indivíduo como categoria moderna (I). Passo então às implicações políticas desse fenômeno (II) e finalizo apontando a formação ideológica que é armada ao se instaurar o falso dilema da cisão entre indivíduo e sociedade (III). A articulação desses três momentos enfatizará no individualismo uma consequência negativa da passagem da ideia de mérito como princípio de conduta individual para um princípio de organização da sociedade.
\end{abstract}

PALAVRAS-CHAVE: Modernidade, mérito, individualismo, sociedade, filosofia social.

ABSTRACT: In this article I develop a narrative that traces the emergence of the idea of merit in a retrospective way, pointing on the passage to Modernity its space of genesis and ascension. For this, I start presenting the emergence of the category of individual as a modern one (I). Then, I trace the political implications of this phenomenon (II) and, in conclusion, emphasize the ideological formation that is stablished by the false dilemma of the split between individual and society (III). The articulation of these three moments will emphasize individualism as a negative consequence of the transition from the idea of merit as a principle of individual conduct to a principle of organization of society.

KEYWORDS: Modernity, merit, individualism, society, social philosophy.

A Modernidade constitui um momento singular da história humana que não se resume em termos meramente cronológicos; mais que isso, ela representa uma ideia de mundo nova, que rompe com a sociedade antiga ${ }^{2}$ e estabelece novos padrões de compreensão da experiência humana, que se articula no desenlace entre a experiência do presente e o horizonte de expectativa, entre fático e crítica, que faz Koselleck (2006, p. 312) enxergar a Modernidade como o "tempo histórico" eminentemente novo: ao fundamentar a si de forma imanente, define assim normativamente o "nosso tempo moderno". É Hegel, no entanto, que toma essa mudança

\footnotetext{
${ }^{1}$ Doutorando em Filosofia pela Universidade Federal de Santa Catarina (UFSC), com financiamento de pesquisa da CAPES. É membro do Núcleo de Ética e Política (Néfipo) da UFSC. E-mail: eduardoburocratico@gmail.com. ${ }^{2}$ Neste trabalho faremos um uso bastante livre de sociedade antiga, ora tratando-a como Antigo Regime, ora como Idade Média, ou como sociedade aristocrática. Embora tenhamos conhecimento de que existem profundas divergências entre estas expressões, as aglutinamos aqui com a finalidade de antepô-las à sociedade Moderna. Em termos sociológicos, a oposição que se deve ter em mente é aquele entre sociedades modernas e sociedades tradicionais.
} 
epocal como a tarefa filosófica fundamental de "apreender em pensamento o seu tempo"3. (HABERMAS, 2000, p. 13)

Do ponto de vista do processo de modernização social, Giddens (1998, p. 94) pensa a Modernidade em três perspectivas distintas e concomitantes: uma postura frente ao mundo onde este encontra-se aberto à transformação pelo homem (de certa forma, o processo de racionalização do mundo); um arranjo de instituições complexas, principalmente aquelas ligadas ao mercado capitalista e um arranjo de instituições políticas que incluem, principalmente, o Estado-Nação e a democracia de massas. Dessa forma, a "postura" moderna pode ser vinculada a uma atitude onde "como em nenhuma outra cultura, vive-se no futuro mais que no passado".

Porém, para mantermos em mente algum tipo de régua-guia, sugiro que esse processo corresponde àquilo que Hobsbawn (2015) chamou de "o longo século XIX": o período que se inicia no ano de 1789 com a Revolução Francesa, acompanhando a Revolução Industrial - a "dupla revolução" de Hobsbawn -, e que só finda com a Primeira Guerra Mundial em 1914. Esse mesmo recorte temporal é chamado por Giddens (1998, p. 96) de "modernidade clássica."

Não é demais lembrar que estas datas não são estanques, fixas, mas apontam para a relação entre espaço e tempo que tomo como referência para a investigação desse texto. $\mathrm{O}$ argumento tentará mostrar que tomada a Modernidade mais como ideia do que intervalo cronológico, encontra-se nela um potencial de desenvolvimento da própria autocompreensão da humanidade como fonte de validação normativa, buscando apontar o sentido no qual há nexo naquilo que, então sim, será o tema desse texto: a emergência do indivíduo como expressão máxima desses tempos modernos e do mérito como princípio de organização dessa sociedade. Para isso, começo apresentando a emergência do indivíduo como categoria moderna (I). Passo então às implicações políticas desse fenômeno (II) e finalizo apontando a formação ideológica que é armada ao se instaurar o falso dilema da cisão entre indivíduo e sociedade (III). Aos conceitos de individualismo e mérito caberá a articulação desses três momentos.

\footnotetext{
${ }^{3}$ Uma discussão nacional sobre o "pioneiro do discurso filosófico da modernidade" opõe aqueles que defendem Hegel, como Marcos Nobre (2019, 2000) e Luiz Repa (2019, 2010, 1996) aos que defendem Kant, como Ricardo Terra (2003). Todos, no entanto, debatem no campo montado por Habermas em O Discurso Filosófico da Modernidade (2000).
} 
Mas o que significa dizer que o indivíduo é uma criação moderna? Talvez a maior marca dessa transformação seja expressa pela interiorização, pela descoberta de que há um mundo subjetivo em cada um, mesmo que se afirme que a "identidade pré-moderna não conhecia as ideias de identidade e reconhecimento, não porque as pessoas não as tinham, evidentemente, mas porque elas não eram questão de importância para elas. (TAYLOR, 1994, p. 30 e 35).

Esse movimento gera no homem uma busca por autenticidade, um ímpeto de dar expressão à sua voz interior. É assim que Hegel (2000, p. 192) toma "o direito da liberdade subjetiva" como ponto central da transição entre a época antiga e a época moderna", o que Charles Taylor, por sua vez, explica nos termos da interioridade:

(...) agora a fonte com a qual temos que nos conectar [para formarmos nossa identidade] encontra-se dentro de nós. Esse fato é parte de uma virada colossal da subjetividade na cultura moderna, uma nova forma de interioridade (inwardness), na qual temos que pensar em nós mesmos como seres com profundidade. A princípio, essa ideia da fonte na interioridade não exclui nossa relação com Deus ou com ideais; mas sim, pode ser considerada como nossa maneira de nos relacionar com eles. (TAYLOR, 1994, p. 29, tradução nossa, grifo nosso)

No entanto, essa "mirada para dentro" não aconteceu de forma arbitrária, como um despertar de uma natureza interior. Há um duplo movimento que antecipa e dá as condições para essa virada: o Renascimento e a Reforma Protestante. Enquanto o primeiro revalidou os valores da autonomia e da razão, a segunda aplicou estes valores às concepções teológicas da vida, tornando Deus uma questão interpretativa do indivíduo ${ }^{4}$.

Fundamental para a efetivação daquilo que viria a ser a noção que até hoje temos do individualismo encontra-se na ideia protestante de vocação $(\text { Beruf })^{5}$ : cabe ao homem, por meio de sua obra, de seus atos e feitos, realizar a missão imposta por Deus. É pela ação virtuosa do indivíduo que se chega à salvação. Portanto, a “institucionalização do individualismo (...) é um fenômeno do mundo ocidental; começou com o cristianismo e foi desenvolvida pela Reforma, e nesta, especialmente por Calvino.” (WATT, 1997, p. 236).

Charles Taylor enxerga nessa passagem a formação de um eu pontual ${ }^{6}$ (pontual self), um ser determinado por sua interioridade, desengajado e desprendido no mundo, e motivando

\footnotetext{
${ }^{4}$ Evidentemente que a Reforma Protestante não aboliu a relação hierárquica do culto e da fé, mas queremos apontar aqui para a ideia que está implícita na primeira sola de Lutero, sola scriputra (apenas por meio da Bíblia).

${ }^{5}$ Embora meu interesse aqui se atenha aos aspectos filosóficos desse processo, uma análise da perspectiva social encontra-se em COHN (2003) e PIERUCCI (2003).

${ }^{6} \mathrm{~A}$ ordem e a plenitude, que nos séculos anteriores competiam à Grande Corrente do Ser, são agora consideradas, no habitual estilo romântico, como algo que diz respeito apenas à vida pessoal do indivíduo; não há virtudes nem vícios fixos. O único princípio operativo de valor é o movimento incessante, qualidade que ele divide com a física moderna, a ética protestante, o jogging e o Marquês de Sade.” (WATT, 1997, p. 209)
} 
essa interioridade por um senso que diz respeito à sua capacidade de se controlar e impor sentido à vida por uma concepção de conhecimento mediada pela razão. (TAYLOR, 1989, p. 160-161)

Tornado o indivíduo senhor do mundo, as recompensas ou danações dos seus atos passam a ser uma consequência do seu próprio agir neste mundo. Tangencio a ideia de mérito, ainda que haja uma diferença entre essa concepção e aquela que hoje concebemos como meritocracia, já que na Modernidade o conceito em si de mérito passa a referir-se a uma outra categoria de coisas: se em sua emergência ele era conferido às ações virtuosas (ações éticas), marcadamente ligadas à salvação divina, na Modernidade o mérito passa a ser definido basicamente em termos de empenho e talento. Se Deus era o reconhecedor dos méritos éticos, na Modernidade é o Estado e o mercado que definem aqueles que ganham e aqueles que perdem (KREIMER, 2000, p. 37). Não à toa Adam Smith trata, na sua Teoria dos Sentimentos Morais (2015), a ação meritória como aquela digna de gratidão, ou seja, sob uma perspectiva daquilo que hoje chamamos de ética das virtudes. Quando falamos de meritocracia como um sistema de ordenação social, não é deste tipo de relação que estamos falando, mas sim de uma relação política talhada pela distribuição dos bônus e ônus daquilo que é fruto da vida em sociedade.

Até aqui só fizemos apontar o nascimento do indivíduo como ideia moderna, uma vez que "o nascimento do conceito de mérito é inseparável do nascimento do conceito de sujeito." (KREIMER, 2000, p. 11, tradução nossa). Resta agora falar um pouco mais sobre o aspecto político desta mudança, sobre como a sociedade aristocrática é transformada pela Revolução Francesa e pela Revolução Industrial. Tem-se a ascensão da sociedade burguesa e, com ela, de sua própria forma de vida, transformando radicalmente as categorias estruturantes da vida em comum: o fim da aristocracia verá a ascensão de uma nova classe social, a burguesia, e com ela, o conceito de estima social será ressignificado por meio do trabalho. Guilhotina-se o sangue e se coroa o suor.

(II)

Se para Hobsbawn (2015, p. 291) “o principal resultado da Revolução na França foi o de pôr fim à sociedade aristocrática", ele mesmo nota que essa cisão não se deu no aspecto ostentatório de marcas e títulos típicos desta sociedade. Na sociedade burguesa, as marcas de exclusividade social (e, consequentemente, da exclusão) apenas mudaram de nome e de classe detentora. O mérito por meio do trabalho e do esforço assume o papel de critério da estima social, transformando-se nas formas ideais de sucesso socialmente visíveis e paradigmática das sociedades modernas. Pois, 
a realização crucial das duas revoluções foi, assim, o fato de que elas abriram carreiras para o talento ou, pelo menos, para a energia, a sagacidade, o trabalho duro e a ganância. Não para todas as carreiras nem até os últimos degraus superiores de escalão, exceto talvez nos Estados Unidos. E, ainda assim, como eram extraordinárias as oportunidades, como estava afastado do século XIX o estático ideal hierárquico do passado! (HOBSBAWN, 2015, p. 302-303).

A Revolução Francesa, em sua própria organização, representou um movimento de abertura da carreira aos talentos, já que, banida a aristocracia de sangue, as promoções e efetivações dentro do exército e da burocracia estatal (principalmente a alta-burocracia letrada) realizavam-se de maneira meritocrática. Nesse expediente se percebe um potencial emancipatório que reside no interior da ideia de mérito: isso porque "quão maiores os domínios onde o indivíduo pode ter sucesso com base apenas em seu esforço, maior será o domínio da igualdade de oportunidades ao acesso de posições sociais". (HARTMANN; HONNETH, 2006, p. 53)

Se a Revolução Francesa legou um vasto manancial simbólico que até hoje é assimilado em nossas representações culturais - pense no lema igualdade, liberdade e fraternidade e em sua longa batalha por efetivação jurídica e política - , seu impacto sobre a organização da sociedade foi muito além da guilhotina e da Bastilha: ela realizou um "giro copernicano sobre a concepção moderna de trabalho - se popularizaram as imagens em que se mostram os trabalhadores em teares, inclusive os associando aos festejos revolucionários." (KREIMER, 2000, p. 14).

Está posta, dessa maneira, a abertura para a sociedade burguesa afluir. Mas o que o pensamento político apreendeu desse processo? De forma esquemática, Kant defendeu que existem apenas duas formas de governo: a república e o despotismo. Sua defesa da forma republicana dá-se por suas características: ela preserva a distinção dos poderes e é representativa. Assim, não havendo quebra dessas cláusulas, não há despotismo. Já quanto aos modos de governo, Kant os distingue em autocracia, aristocracia e democracia, que se diferenciam justamente pelo critério da representação, ou seja, quem é o governante. (KANT, 2006, p. 69)

Porém, mais importante para nossa discussão é a caracterização que Kant faz "dos atributos jurídicos inseparáveis de sua natureza" de cidadãos (cives) em uma república: 1) possuir liberdade legal de não obedecer a nenhuma lei que não assentiram; 2) possuir igualdade civil, perante a lei e, portanto, aos outros 3) a independência civil de não dever sua existência a outrem. (KANT, 2014, p. 128-129). Se não há obrigação de cumprir uma máxima heterônima, isto é, alheia à liberdade, a qualidade da igualdade civil desclassifica o Ancien Régime, pois já não são mais permissíveis desigualdades que afrontem a igualdade civil do cidadão. Entretanto, 
os requisitos para a mobilidade social em Kant são altamente meritocráticos, já que a última qualidade implica uma cláusula: só é cidadão ativo aquele que possui independência financeira. Meu ponto aqui, mais do que analisar a concepção kantiana, é tirar as consequências que o colocam como um avatar de filosofia burguesa e da burguesia:

\begin{abstract}
No que respeita ao direito de igualdade de todos os cidadãos enquanto súditos, importa responder à questão da admissibilidade da nobreza hereditária: se a classe concedida pelo Estado (a classe de um súdito sobre outro) deve preceder ao mérito ou ao contrário. - Uma coisa é clara: se a classe vai vinculada ao nascimento, não é totalmente certo que o mérito (capacidade e fidelidade profissionais) venha depois: isto é como se lhe concedesse ao beneficiado o ser chefe sem os méritos, com o que nunca concordará a vontade geral do povo em um contrato originário (que é, sem dúvida, o princípio de todos os direitos). Um nobre não é necessariamente, pelo fato de sê-lo, um homem nobre. - No que diz respeito à nobreza de cargo (como poderia chamar-se à classe de uma magistratura elevada e que deve ser alcançada por méritos), a classe não pertence à pessoa como uma propriedade, mas ao posto, e a igualdade não se lesiona por isso: ao abandonar o cargo, esta pessoa deixa, ao mesmo tempo, a classe e regressa ao povo. (KANT, 2006, p. 68)
\end{abstract}

Fazendo frente aos direitos aristocráticos adquiridos no nascimento, a dupla revolução instituiu a carreira aberta aos talentos como o télos da reforma da sociedade. É interesse do burguês que, não nascendo sob o sobrenome certo, tome-se outro critério que não o berço como ideal normativo:

\footnotetext{
Os direitos hereditários deveriam desaparecer para que cada indivíduo ocupasse na sociedade o lugar que lhe conferisse seu próprio mérito, um valor de legitimação estritamente referido ao universo do trabalho e do saber que compreende o esforço, a destreza, a qualificação e a experiência. (KREIMER, 2000, p. 13).
}

Como ilustra Hobsbawn (2015, p. 303) “em 1750, o filho de um encadernador de livros teria, com toda probabilidade, se agarrado ao ofício do pai. Agora não era mais obrigado ao fazê-lo”. Não há dúvida, no entanto, que o ponto nevrálgico é a não-obrigação de fazê-lo, uma vez que sabemos que as coisas mudaram, ainda que não tenham mudado tanto assim. Pois quais seriam, então, as opções (ao menos formais) que o filho do encadernador de livros poderia assumir nessa nova sociedade que se formava? Hobsbawn (2015, p.303-305) as classifica em quatro: os negócios, a educação (que levava a três metas: o funcionalismo público, a política e as profissões liberais), as artes e a guerra. Contudo, o historiador afirma que, dentre estas, eram a educação e os negócios que melhor representavam as carreiras abertas ao talento, uma vez que o faziam por sistemas de exames - ainda que "como outras formas de competição individualista, prestar exame era um recurso liberal, mas não democrático ou igualitário."

Mas, se o rei morto pôs a burguesia no trono da pirâmide social, desde Hegel sabemos que o sujeito moderno, o sujeito da autoconsciência, trava sua luta por reconhecimento de forma intersubjetiva, ou seja, mediada socialmente. E, mais que isso, a sociedade cristaliza em suas instituições as formas sociais deste reconhecimento (contra as quais os indivíduos levantam 
suas pretensões de reconhecimento). Portanto, é preciso agora analisar os sentidos de honra na sociedade antiga e de estima social (nas palavras de Axel Honneth) ou dignidade (conforme Charles Taylor) sobre os quais os indivíduos modernos constroem suas identidades, ambos inspirados em Hegel.

Honneth (2003, p 201) marca esse processo de transformação histórica afirmando que

a estima social só pode assumir a forma que nos é familiar hoje depois que se desenvolveu a ponto de não caber mais nas condições limites das sociedades articuladas em estamentos. A mudança estrutural que isso pôs em marcha é marcada, no plano de uma história conceitual, pela transição dos conceitos de honra às categorias da "reputação" ou "prestígio" social.

Na adição ao parágrafo 207 da Filosofia do Direito, Hegel esclarece que "dizendo que o homem tem que ser algo, entendemos que ele pertence a uma classe determinada, pois este algo quer dizer que ele é, então, algo substancial.” Ele considera que cada indivíduo escolhe em liberdade sua ocupação, e que essa é uma marca distintiva do Ancien Régime. No entanto, no trânsito da família para a sociedade civil, Hegel (2000, p. 249-250) enfatizava que o mal da sociedade moderna é a parcialidade oriunda da fragmentação dos indivíduos na sociedade civil, ou seja, sua perda de eticidade se dá justamente no momento em que a sociedade burguesa atomiza os indivíduos como seres privados $d o$ sistema de carências.

Tomado pelo motivo hegeliano, Charles Taylor (1994, p. 26-27) afirma que são duas as razões que colocam as questões da identidade e do reconhecimento como inevitáveis para o pensamento moderno. A primeira seria o já mencionado colapso das hierarquias sociais em que se baseavam a honra, sendo ela entendida em ligação direta com as iniquidades, pois "para alguém possuir honra neste sentido é imprescindível que nem todos a tenham.” A segunda razão é que, em oposição à honra, a noção moderna de dignidade se baseia na ideia de universalidade e igualdade, ou seja, em uma concepção de dignidade cidadã. Portanto, sob a imposição do valor igual da vida humana na modernidade o conceito desigual da honra é posto de lado pelo conceito recíproco (e que, portanto, busca ser reconhecido) da dignidade.

Mas se o médium social do reconhecimento passa a ser o trabalho, é preciso fazer a crítica das possibilidades de reconhecimento na esfera do sistema das carências, no sistema de cooperação que produz e reproduz a vida social por meio do mercado. Deve-se perseguir as relações ambíguas que a efetivação do trabalho como fonte de estima social impõe, de como o surgimento de uma classe - a burguesia - encontra a necessidade de criar, como uma teodiceia de sua própria ascensão, um padrão específico de legitimação simbólica, de como se passa, pois, à ideologia:

A luta da burguesia contra as coerções comportamentais, específicas aos estamentos e impostas pela antiga ordem de reconhecimento, leva a uma individualização na 
representação de quem contribui para a realização das finalidades éticas: uma vez que não deve ser mais estabelecido de antemão quais formas de conduta são consideradas eticamente admissíveis, já não são mais as propriedades coletivas, mas sim as capacidades biograficamente desenvolvidas do indivíduo aquilo por que começa a se orientar a estima social. (...) O lugar que o conceito de honra havia ocupado antes no espaço público da sociedade passa então a ser preenchido pouco a pouco pelas categorias de "reputação" ou de "prestigio", com as quais se deve apreender a medida de estima que o indivíduo goza socialmente quanto a suas realizações e a suas capacidades individuais. (HONNETH, 2003, p.205-206, grifo nosso)

Como até aqui tentei mostrar, ao passo que a ideia de mérito como um critério normativo da estima social na Modernidade tem como contraparte o próprio centramento do homem como indivíduo moderno, parecem ficar um pouco mais claras as implicações negativas que o mérito individual passa também a possibilitar: se, por um lado, ele rompe com a noção aristocrática de honra, com a desigualdade formalmente reconhecida, ao propor a carreira aberta aos talentos e ao esforço, todo o peso da vida do homem está agora sobre seus próprios ombros. Novamente, na letra de Hobsbawn (2015, p.317):

A sociedade hierárquica era, assim, reconstruída sobre os princípios da igualdade
formal. Mas havia perdido o que a fazia tolerável no passado, a convicção social geral
de que os homens tinham deveres e direitos, de que a virtude não era simplesmente
equivalente ao dinheiro, e de que as classes mais baixas, embora baixas, tinham direito
a suas modestas vidas na condição social a que Deus os havia chamado.

Neste momento, a Revolução Industrial e o surgimento do capitalismo, ao tornarem cada homem e mulher fonte de trabalho individualizado que só se encontra fragmentariamente no mercado, lançam esses mesmos homens e mulheres não só a uma luta de todos contra todos, uma vez que não há ocupação para todos, mas também numa luta de todos contra si mesmos, já que são eles e elas os responsáveis pelo cultivo de seus talentos e aptidões, e por consequência também os responsáveis últimos por seus méritos e deméritos.

Também não é fortuito que o surgimento do Estado-nação moderno coincida com essa mudança na economia. Os fisiocratas franceses, mais contadores nacionais que economistas ${ }^{7}$, ajudaram a fundar aquilo que se cristalizaria como outra marca indelével do século XVIII, a economia política como forma de ação do Estado sobre a produção e a organização social.

O protagonismo da economia política parece apoiar-se em um interesse que será central: a economia agora passa a se pautar pelos meios de gerir esse produto social; o homem, que se antes não tinha particularidade, tinha respeitado sua mínima condição de sobrevivência, agora é um recurso à disposição da sociedade ${ }^{8}$. Ou como bem sintetiza Kreimer (2000, p. 176, tradução nossa): “A implantação do ideal burguês de vocação revela o triunfo da cidade sobre o campo, do trabalho intelectual sobre o manual no âmbito da economia e na esfera simbólica

\footnotetext{
${ }^{7}$ Tome-se como exemplo germinal o Tableau économique, de François Quesnay.

${ }^{8}$ Como o próprio Hegel já observara no parágrafo 245 de sua Filosofia do Direito.
} 
da luta por reconhecimento." O indivíduo que nascera no começo dessa seção, desprendido no mundo e senhor dele, chega nestas páginas como um homem que pode formalmente conquistar este mundo, mas que só dispõe de seus próprios braços para fazê-lo.

\section{(III)}

Se a sociedade burguesa do esforço e do talento despojou a sociedade hierárquica, seu ideal de igualdade entre todos os indivíduos enquanto seres autônomos, o próprio princípio kantiano do "homem como fim em si", nunca passou de uma promessa9 . Polanyi (1980, p. 173) nos mostra que os movimentos do mercado, desde sua forma laissez-faire, nunca foram um princípio natural, uma ordem do divino desígnio, e que tampouco o homem se realiza de forma atomizada no mundo. Por ora, a intenção é mostrar que essa emergência do individualismo, do credo no homem que se faz por sua única e própria conta, torna-se tão poderosa que forma, de fato, uma nova forma de justificação da ordem social. Mas não se perca de vista que, neste caso, mudar o mundo é apenas mudar o mundo de lugar. Isso porque o que se viu foi a substituição de um tipo de desigualdade por outro. Se há um progresso em deixarmos de separar e determinar vidas por questões de nascimento, precisamos avaliar até que ponto a nova sociedade não separa e determina vidas por talento e empenho.

Atribuir o produto do trabalho social e posições e cargos de acordo com o mérito pode até corresponder a uma ideia intuitiva, mas, como toda ideia intuitiva, é necessário o escrutínio. A “metafísica do mérito” (KREIMER, 2000, p. 172), a confiança desmedida na educação e no esforço individual, obscurece uma série de desigualdades que podem estar presentes. E enquanto houver desigualdade moralmente arbitrária, aquela que não podemos legitimar num contexto de justificação universal e recíproco, existe uma fonte de injustiça.

É por isso que a máxima “a cada um segundo seus méritos" pode, sim, ser um princípio de eficiência no sentido econômico, ou seja, um parâmetro de maximização. No entanto, um princípio de eficiência não implica um princípio de justiça automaticamente ${ }^{10}$. E essa constatação se coaduna com uma premissa maior: atribuir mérito a um indivíduo implica definirmos o que é uma ação meritória. É evidente que nossa sociedade valoriza determinadas atitudes, aptidões e talentos mais que outras. Entretanto, como tentei mostrar, muito dessa valorização é uma transposição dos valores específicos de uma classe, a burguesia, e, portanto,

\footnotetext{
${ }^{9}$ A denúncia da insuficiência da igualdade formal de oportunidades já fora feita por Marx e Rousseau de forma contundente, não obstante, ainda hoje muito do debate político sobre a igualdade gira em torno do dilema "igualdade formal x igualdade substantiva."

${ }^{10}$ Esse tipo de crítica faz coro à recusa ao utilitarismo como critério de justiça social.
} 
de seus interesses, para algo com caráter de valor intrínseco. Mas o estranhamento surge quando esses interesses propagados se chocam com questões básicas: se é o mérito que deve ser o valor final de avaliação, o quão responsável um indivíduo é por seu merecimento? Ou ainda, quais são as possibilidades epistemológicas de, dentro de uma trajetória de vida, apontarmos as ações e méritos próprios que condizem apenas ao indivíduo, e que não teriam a influência de fatores que não lhe são de direito?

O insuspeito Frederich Hayek ${ }^{11}$ parece ter captado a essência da questão:

Sem dúvida é importante que, na ordem de mercado (ou sociedade fundada na livre iniciativa, enganosamente chamada de "capitalismo"), os indivíduos acreditem que seu bem-estar depende, em essência, de seus próprios esforços e decisões. De fato, poucas coisas infundirão mais vigor e eficiência a uma pessoa que a crença de que a consecução das metas por ela mesma fixadas depende sobretudo dela própria. Por isso tal crença é frequentemente encorajada pela educação e pela opinião dominante - em geral, ao que me parece, para grande benefício da maior parte dos membros da sociedade em que reina, os quais deverão muitos progressos materiais e morais importantes a pessoas por ela guiadas. No entanto, sem dúvida essa crença gera também uma confiança exagerada na verdade dessa generalização que, para os que se consideram (e talvez sejam) igualmente hábeis, mas fracassaram, parecerá uma amarga ironia e grave provocação. (HAYEK, 1985, p. 93-94, grifo nosso)

Considerando a extensa citação de Hayek, chega a ser irônico o fato de que ele, o autor de cabeceira daquele pensamento que hoje chamamos de neoliberalismo econômico, trate a questão do mérito de forma tão cortante. Afinal, é empregada a expressão crença, e é nesse sentido que finalizo a exposição do argumento. Essa "narrativa retrospectiva" da ideia de mérito mostra que aquilo que fora gestado como uma crítica incisiva ao establishment vigente transforma-se em nossos dias numa verdadeira estratégia ideológica de justificação do status quo, perdida a oportunidade de aprofundar radicalmente a ideia de igualdade de oportunidades e vendo tomar espaço um individualismo ensimesmado e apolítico.

Ian Watt (1997, p. 227), analisando quatro personagens que seriam a marca fundadora do mito do individualismo moderno (Fausto, Dom Quixote, Dom Juan e Robinson Crusoé), evidencia que, na transformação dessas narrativas, os fatos do espírito que antes eram negativos e condenados à danação são agora estimulados: aquilo que antes era ofensa moral digna de punição, transmutou-se em objeto de admiração. Agora o indivíduo passaria de mero joguete do destino, na expressão shakespeariana, para tornar-se senhor dele.

\footnotetext{
${ }^{11}$ No capítulo VI de Os fundamentos da liberdade, Hayek aborda especificamente a questão do mérito frente a noção de valor e igualdade, concluindo pela impossibilidade de estabelecimento do mérito enquanto um valor, já que "mérito não implica qualquer resultado objetivo mas um esforço subjetivo." (HAYEK, 1983, p. 102-103)
} 
Ao qualificar os quatro "heróis" citados, talvez Watt (1997, p. 233) nos forneça uma rica descrição do típico herói do capitalismo, o self-made-man, uma forma patológica daquele individualismo que já foi amplamente enfrentado:

\begin{abstract}
Isso acontece em parte pelo fato de nossos quatro heróis serem monomaníacos; nenhum deles está particularmente interessado em outra pessoa; estão, isto sim, voltados exclusivamente para os seus empreendimentos pessoais; assim, eles se definem mediante aquilo que de alguma forma decidiram fazer ou ser. Fausto, Dom Juan e Robinson Crusoé são basicamente solitários; e como Sancho Pança, contaminado pelas ideias do amo acaba por adotá-las como parte de seu próprio eu, Quixote e Pança tornam-se uma dupla de solitários.
\end{abstract}

Como falei de um tipo patológico, vale pensar rapidamente no caso Sancho Pança: embora fosse ele o lado racional da dupla, é ele também que adere aos loucos sonhos de Quixote por promessas vagas da conquista de uma ilha, e de quem sabe lá chegando, tornar-se rei do lugar. Para isso, larga até mesmo família e amigos. É esse comportamento egoísta e ensimesmado, que vê na sociedade um mero meio para a sua própria autorrealização, que parece ser o mesmo tipo de comportamento que fez do mérito um valor social tão pouco escrutinado, mas estranhamente defendido. Ele se impõe sem se questionar porque apela pra aquilo que há de constitutivo em nós, em nossa capacidade e desejo de realizar planos e objetivos e de sermos reconhecidos enquanto individualidades. Mas sua narrativa passa a ser um entrave para a própria realização dessa possibilidade, uma vez que vê na sociedade um inimigo da autonomia individual, e não como aquilo que é, sua própria condição.

Não é preciso se alongar mais na reafirmação do caráter ideológico da narrativa do homem que faz seu próprio destino, que por seus méritos e só por eles dobra a roda da fortuna a seu favor. Polanyi (1980) mostra claramente como esse tipo de fantasia não passa disso, uma vez que o mercado e o Estado formam um mesmo sistema, “a economia de mercado". É justamente nesse ponto, nessa ideologia do mérito, que reside sua perversão: ao articular a ideia de indivíduo e sociedade pela perspectiva do primeiro, assume um tipo de individualismo epistemológico que implica uma teoria da sociedade que acaba por modelar um comportamento egoísta antropologicamente fundamentado, tendo como resultados colaterais um sistema social que perverte a autonomia em nome da fragmentação. O que inicia como um potencial de emancipação da sociedade moderna acaba por se voltar contra suas próprias intenções.

\title{
REFERÊNCIAS BIBLIOGRÁFICAS
}

COHN, G. Crítica e resignação. Max Weber e a teoria social. São Paulo: Editora Martins Fontes, 2003

GIDDENS, A. Conversations with Anthony Giddens: Making Sense of Modernity. Stanford, Calif.: Stanford University Pres, 1998. 
HABERMAS, J. O discurso filosófico da modernidade. São Paulo: Martins Fontes, 2000 HARTMANN, M.; HONNETH,. "Paradoxes of capitalism”. In: Constellations, v. 13, n. 1, p. 41-58, 2006

HAYEK, F. A. v. Direito, Legislação e Liberdade. Vol. 2. A miragem da justiça social. São Paulo: Visão, 1985

HAYEK, F. A. v. Os fundamentos da liberdade. São Paulo: Visão, 1983.

HEGEL, G. W. F. Rasgos fundamentales de la Filosofia Del Derecho. Madri: Biblioteca Nova, 2000 .

HOBSBAWM, E. J. A Era das Revoluções (1798-1848). Rio de Janeiro: Paz \& Terra, 2015.

HONNETH, A. Luta por reconhecimento: a gramática moral dos conflitos sociais. São Paulo : ed. 34,2003

KANT, I. A Paz Perpétua: Um Projecto Filosófico. Covilhã: LusoSofia, 2006

KANT, I. Princípios metafísicos da doutrina do direito. São Paulo: Editora WMF Martins Fontes, 2014

KOSELLECK, R. Futuro passado: contribuição à semântica dos tempos históricos. Rio de Janeiro: Contraponto: Ed. PUC-Rio, 2006

KREIMER, R.. História del mérito, 2000. Disponível em: https://www.filosofiaparalavida.com.ar/Historia_del_merito_libro.pdf. Acesso em: 15 setembro de 2020.

NOBRE, M. Como nasce o novo. São Paulo: Todavia, 2019

NOBRE, M. Permanecemos contemporâneos dos jovens hegelianos: Jürgen Habermas e a situação da consciência atual. In: Revisa Olhar, São Carlos, vol. 4, ano 2, dez-2000

PIERUCCI, A. F. O desencantamento do mundo: todos os passos do conceito em Max Weber. São Paulo, Editora 34, 2003.

POLANYI, K. A grande transformação: as origens de nossa época. Rio de Janeiro, Campus, 1980.

REPA, L. A essência da crítica: sobre o limiar da crítica imanente em Hegel. In: DISCURSO, v. 49, p. 269-285, 2019

REPA, L. Hegel, Habermas e a Modernidade. In: Dois Pontos (UFPR), v. 7, p. 151-162, 2010

REPA, L. Notas sobre a contemporaneidade dos jovens hegelianos. In: Cadernos de Filosofia Alemã, São Paulo, v. 1, p. 5-26, 1996

TAYLOR, C. Sources of the Self: The Making of Modern Identity. Cambridge: Harvard University Press, 1989

TAYLOR, C. The Politics of Recognition. In: GUTMANN, A. (ed.). Multiculturalism: Examining the Politics of Recognition. Princeton : Princeton University, 1994

TERRA, R. Passagens: estudos sobre a filosofia de Kant. Rio de Janeiro: Editora UFRJ, 2003

WATT, I. Mitos do individualismo moderno. Rio de Janeiro, Jorge Zahar Editor, 1997. 